\title{
Sluicing cannot apply in-situ in Japanese
}

\section{Ken Hiraiwa*}

\begin{abstract}
Ross (1969) proposed that sluicing in English is derived by whmovement and deletion. The wh-movement analysis, however, is not straightforwardly applicable to in wh-in-situ languages like Japanese. A number of studies argued that sluicing in Japanese is based on wh-cleft structure with much empirical evidence. More recently, however, Kimura (2010) and Abe (2015) have proposed an in-situ analysis of sluicing in Japanese, which deletes everything but a wh-phrase (and the Q-complementizer) in situ, without movement. In this paper, building on immobile elements, I will provide decisive evidence against the in-situ deletion analysis of sluicing and for the wh-cleft analysis of sluicing.
\end{abstract}

Keywords. sluicing; deletion; ellipsis; wh-movement; wh-cleft; in-situ; existential indeterminates; Japanese; syntax

1. Introduction. As is well known, Ross (1969) proposed that a truncated wh-question such as example (1) has a full-fledged structure of wh-question and is derived from wh-movement and deletion. He called the phenomenon sluicing.

(1) Somebody just left. Guess who just left.

Whether sluicing in a wh-in-situ language like Japanese has the same syntactic derivation or not has been lively discussed in the literature, and three analyses have been proposed: a whmovement analysis, a wh-cleft analysis, and an in-situ deletion analysis: In this short article, I will provide evidence for a wh-cleft analysis of sluicing and, crucially, against the in-situ deletion analysis (Kimura 2010 and Abe 2015, 2016) (and the wh-movement analysis).

2. Three Approaches to Sluicing in Japanese. Inoue (1976) observed that a similar truncated wh-question also exists in Japanese. Takahashi (1994) adopt the same analysis for it, in which TP-deletion applies after wh-movement (see also Takita 2009).

(2) Wh-movement+Deletion

(Context: I know that Mary bought something there, but)

[Nani-o 1 [-Mary ga sokede $t_{1}$ katta] ka] siranai.

what-Acc Mary-Nom there bought Q 1Sg.know.Neg

'I don't know what Mary bought there.'

This analysis assumes that a wh-phrase moves to the specifier of CP in Japanese, just as it does in English.

For wh-in-situ languages such as Japanese, however, an application of the wh-movement analysis is not straightforward due to the lack of overt wh-movement (see Merchant \& Simpson 2012). In fact, many have argued against such an analysis of sluicing in Japanese, pointing to the facts that a copula optionally appears a pronominal subject is grammatical in sluicing in Japanese (Nishiyama et al. 1996, Kuwabara 1997, Fukaya \& Hoji 1999, Saito 2004, Kizu

\footnotetext{
* I am grateful to Tomo Fujii, Kimiko Nakanishi, Tommy Tsz-Ming Lee, and the audience of the LSA 2021 annual meeting for helpful questions and comments. This research has been funded by the JSPS Grant-inAid for Scientific Research (C) (No. 20K00554), to which I am grateful. Author: Meiji Gakuin University (hiraiwa@ltr.meijigakuin.ac.jp).
} 
2005, and Hiraiwa \& Ishihara 2012). Furthermore, a negative polarity item is disallowed in stripping and cleft (Hiraiwa \& Ishihara 2012).

(3) Sluicing with a copula

[Nani-o (da) ka] siranai.

what-Acc Cop Q 1Sg.know.Neg

'I don't know what (it was).'

(4) Sluicing with a pronominal subject

[Sore-ga nani-o (da) ka] siranai.

it-Nom what-Acc Cop Q 1Sg.know.Neg

'I don't know what it was.'

(5) Stripping (Hiraiwa \& Ishihara 2012)

(Context: Although I hear that Naoya did not called some of the people that he was supposed to call after all $)^{1}$

*[Dare-ni-mo (da) ka (wa)] siranai.

who-Dat-also Cop Q Top 1Sg.know.Neg

'I don't know if he didn't call anyone.'

The data in (3)-(5) are unexpected under the wh-movement analysis of sluicing, because whmovement introduces neither a copula nor a pronominal subject and is compatible with a negative polarity item.

Rather, they indicate that sluicing in Japanese has a cleft structure. More specifically, sluicing in Japanese has a wh-cleft structure, from which the topicalized clause is deleted. ${ }^{2}$

Wh-Cleft+Deletion

[ [Mary-ga sokode $t_{1}$ katta no] wa nani-o ${ }_{1}$ (da) ka] siranai.

Mary-Nom there bought C-Top what-Acc Cop Q 1Sg.know.Neg

'I don't know what (it was) that Mary bought there.'

More recently, however, Kimura (2010) and Abe $(2015,2016)$ have argued for an in-situ deletion analysis of sluicing in which deletion applies to non-constituents without any movement (see also den Dikken et al. 2002 and van Craenenbroeck \& den Dikken 2006). In this analysis, a wh-sluice does not need to move and deletion applies to everything but the whphrase in-situ. They also proposed the same analysis for wh-movement languages like English.

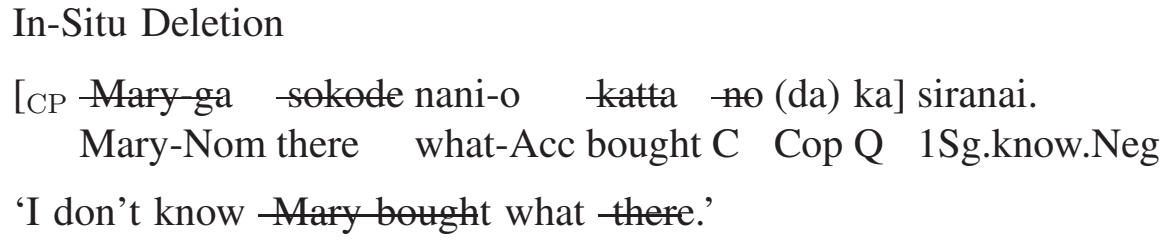

\footnotetext{
${ }^{1}$ See Section 3.2 for similar evidence from sluicing. Hiraiwa \& Ishihara's argument based on the stripping example in (5) was indirect in the sense that they assumed that stripping has the same syntactic mechanism as sluicing.

${ }^{2}$ Whether the wh-cleft structure involves null operator movement (Nishiyama et al. 1996, Kuwabara 1997,

Fukaya \& Hoji 1999, Saito 2004, Kizu 2005) or overt movement (Hiraiwa \& Ishihara 2012) is immaterial here.
} 
This in-situ deletion analysis has gained some popularity in the literature (see Sato 2016, Kimura \& Narita 2021).

3. A Prediction: Immobility and Deletion. A simple logical prediction arising from the three analyses is this. Suppose that there is a wh-element X that is "immobile" (the definition of immobility here: $\mathrm{X}$ is immobile iff it cannot be clefted). If sluicing with $\mathrm{X}$ is grammatical, then it tells against the wh-cleft analysis of Japanese sluicing. On the other hand, if sluicing with $\mathrm{X}$ is ungrammatical, then it provides evidence against the in-situ deletion analysis and the wh-movement analysis of Japanese sluicing.

In this paper, I present very simple evidence that clinches the debate in favor of the whcleft analysis of sluicing in Japanese over the other two analyses.

3.1. Wh-AdJUnCts 'WhY'. Japanese has various lexical items for asking a reason: not just morphologically simplex naze, but also morphologically complex nande, and doosite (see Fukui 1998, Fujii et al. 2014). But there are also other forms such as nandemata and nandatte.

(8) [John-ga \{naze/nande/doosite/nandemata/nandatte $\}$ Mary-ni atta no (da) ka]

John-Nom why Mary-Dat met C Cop Q

siranai.

1Sg.know.Neg

'I don't know why John met Mary.'

Positions of these wh-adjuncts are free both in matrix and embedded clauses. They can be in clause-medial position as shown in (8) or in clause-initial position, as shown in (9).

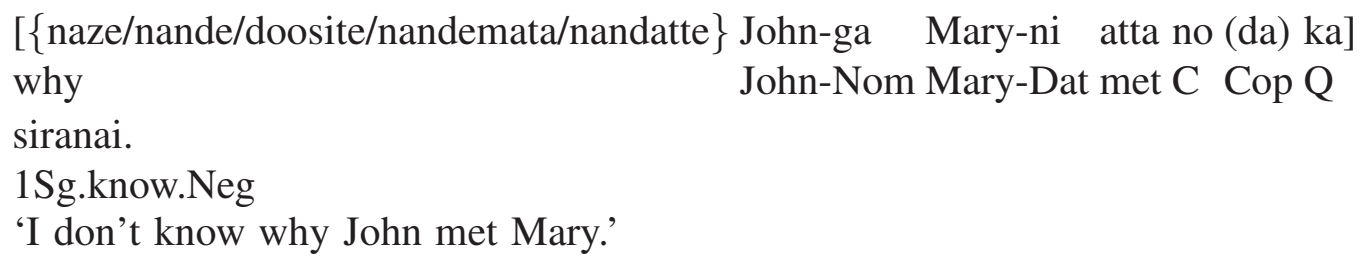

Whether the clause-initial word order in (9) is due to scrambling/wh-movement (Takahashi 1994) or base-generation (Ko 2005) is immaterial for us. Rather, of special importance here is the fact that nandemata and nandatte cannot be clefted, as shown in (10).

(10) Wh-Cleft

[[John-ga Mary-ni atta no]-wa \{naze/nande/doosite/*nandemata/*nandatte (da) ka]

John-Nom Mary-Dat met C-Top why

Cop Q

siranai.

1Sg.know.Neg

'I don't know why it was that John met Mary.'

Of course, it is not the case that wh-adjuncts in general cannot be clefted in Japanese. Note that naze, nande, and doosite are grammatical in wh-cleft sentences.

Having established that nandemata and nandatte are immobile, now let us examine if sluicing is grammatical or not. As the examples in (11) show, sluicing with the immobile whadjuncts nandemata and nandatte is indeed ungrammatical, while sluicing with naze, doosite, and nande is perfectly grammatical. 


\section{(11) Sluicing}

(Context: I know John met Mary for a reason, but)

[[John Mary ni atta no] wa $\{$ naze/nande/doosite/*nandemata/*nandatte $\}$ (da) ka] John-Nom Mary-Dat met C-Top why siranai.

1Sg.know.Neg

'I don't know why (it was) that John met Mary.'

Similarly, in matrix fragment questions, nandemata and nandatte also sound terribly bad, while the others are all fine.

\section{(12) Fragment Question}

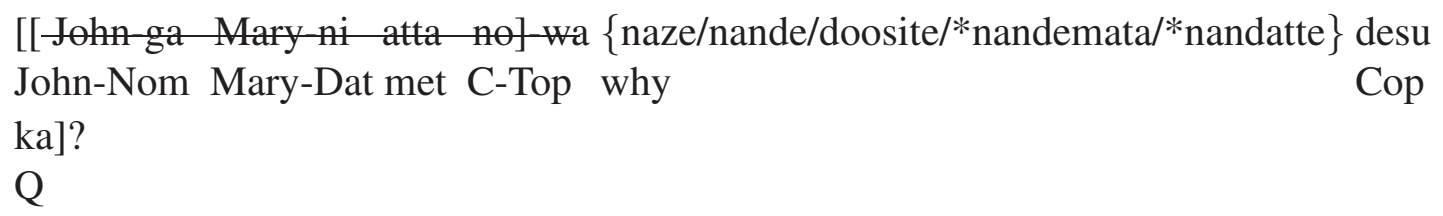

The immobile wh-adjuncts present clear and conclusive evidence that Japanese does NOT allow in-situ sluicing. If UG allowed for a mechanism of in-situ sluicing, which would delete non-constituents freely, the examples like (11)-(12) would be grammatical irrespective of the kinds of wh-adjuncts.

The immobile wh-adjuncts also argue against the wh-movement analysis of sluicing in Japanese. As the data in (8) and (9) show, word order of those wh-adjuncts is free. Therefore, the wh-movement analysis should predict the all wh-adjuncts to be grammatical in (11)-(12). Note also that my argument does not depend on whether a wh-cleft derivation involves direct movement of a focused phrase (Hiraiwa \& Ishihara 2012) or a null operator movement (Nishiyama et al. 1996, Kuwabara 1997, Fukaya \& Hoji 1999, Saito 2004, Kizu 2005), because the fact still remains anyway that wh-cfleft of nandemata and nandatte are ungrammatical.

One might entertain a possibility that whether or not wh-cleft is possible is somehow related to whether wh-adjuncts in question are morphologically complex or not. Clearly, the immobile wh-adjuncts nandemata and nandatte are morphologically complex, consisting of nande-mata 'what-P-again' and nan-datte 'what-Cop', respectively. But it is worth noting that actually, all the wh-adjuncts above (except naze) are morphologically complex: nan-de 'what-P' and doo-site 'how-do'.

Furthermore, these immobile wh-adjuncts seem to be one word. Fujii et al. (2014) correctly show that nandemata exhibits a compound pitch accent.

$$
\text { na'ndemata (HLLLL) }
$$

Thus, the morpheme mata of nandemata does not have the meaning 'again' when used as a wh-adjunct. This contrasts with the interpretation when nande and mata are syntactically detached. In such a case, they are pronounced na'nde (HLL) and mata (LH), respectively (cf. (13)). 
(14) [Nande John-ga mata Mary-ni atta no (da) ka] siranai.

why John-Nom again Mary-Dat met C Cop Q 1Sg.know.Neg

'I don't know why John met Mary again.'

In summary, the immobile wh-adjuncts demonstrate that UG prohibits in-situ sluicing for Japanese, contrary to the recent claims by Kimura (2010) and Abe (2015, 2016). Rather, whenever clefting is blocked, sluicing is also blocked, supporting the claim that sluicing in Japanese is structurally derived from wh-cleft.

3.2. NCI sika. There is another piece of evidence against the in-situ deletion analysis and the wh-movement analysis of sluicing in Japanese. sika is a negative concord item (NCI) that requires clause-mate negation (see Tanaka 1997 on the sika ... nai construction and Watanabe 2004 for NCIs in Japanese).

(15) John-wa niku-sika tabe-nai/*taberu.

John-Top meat-NCI eat-Neg/eat

'John does not eat anything but meat.'

While they can be freely scrambled, as Hiraiwa \& Ishihara (2012) observe, NCIs cannot be clefted.

a. Niku-sika $\mathrm{J}_{\mathrm{i}} \mathrm{John-wa} \mathrm{t}_{\mathrm{i}}$ tabenai.

meat-NCI John-Top eat.Neg

'John does not eat anything but meat.'

b. *[John-ga tabenai no]-wa niku-sika desu.

John-Nom eat.Neg C-Top meat-NCI Cop

'(Lit.) It is anything but meat that John does not eat.'

Now, if the NCI sika is combined with a wh-phrase nani 'what', we get a wh-question sentence as in (17a). Note that nani-sika 'what-NCI' can also be scrambled as shown in (17b). But crucially, it cannot be wh-clefted, as (18) shows. Thus, this NCI is another immobile element.

a. John-wa nani-sika tabe-nai no?

John-Top what-NCI eat-Neg C

'(Lit.) Anything but what does John not eat?'

b. Nani-sika $\mathrm{J}_{\mathrm{i}}$ John-wa $\mathrm{t}_{\mathrm{i}}$ tabe-nai no?

what-NCI John-Top eat-Neg C

'(Lit.) Anything but what does John not eat?'

Wh-Cleft

*[John-ga tabe-nai no]-wa nani-sika desu ka?

John-Nom eat-Neg C-Top what-NCI Cop Q

'(Lit.) Anything but what is it that John does not eat?'

Again, sluicing is disallowed in this case, too.

(19) Sluicing

(Context: I know that John does not eat anything but something, but) 
*[[John-ga tabe-nai -no] wa nani-sika (da) ka] siranai.

John-Nom eat-Neg C-Top what-NCI Cop Q 1Sg.know.Neg

'(Lit.) I don't know anything but what (it is) that John does not eat.'

The ungrammaticality of (19) offers another piece of strong evidence against the in-situ deletion analysis (as well as the wh-movement analysis) in favor of the wh-cleft analysis. ${ }^{3}$

4. Existential Indeterminates and Sluicing. I have demonstrated that sluicing in Japanese is built on a wh-cleft structure. Existential indeterminates lends further support for this conclusion. Japanese composes various indefinite expressions by combining a wh-indeterminate and a particle (see Kuroda 1965, Shimoyama 2008, Hiraiwa 2015, 2017). Existential indeterminates are built with a wh-indeterminate and the particle $k a$.
a. dare-ka 'someone'
b. nani-ka 'something'
c. doko-ka 'someplace'

The indeterminates for wh-adjuncts 'why' are no exception.
a. naze-ka 'for some reason'
b. nande-ka 'for some reason'
c. doosite-ka 'for some reason'

However, it is very interesting that those immobile wh-adjuncts cannot form existential indeterminates. ${ }^{4}$
a. *nandemata-ka 'for some reason'
b. *nandatte-ka 'for some reason'

It has been generally assumed that such existential indeterminates as (20)-(21) are categorically nominal. Contrary to the standard view, however, Hiraiwa \& Nakanishi to appear, and Hiraiwa (2020) argue that existential indeterminates in Japanese and Okinawan are syntactically clausal and derived from a wh-question structure by sluicing and dunno-deletion (cf. Haspelmath 1997). ${ }^{5}$

(23) So-called existential indeterminates in Japanese and Okinawan are syntactically derived from an embedded wh-question by sluicing and dunno-deletion. (Hiraiwa \& Nakanishi to appear, and Hiraiwa 2020)

$$
\begin{aligned}
& \text { [(-Sore-ga) dare (da) ka] sira-nai } \\
& \text { 3Sg-Nom who Cop C know-Neg } \\
& \text { 'someone (lit. I don't know who it is)' }
\end{aligned}
$$

Crucial evidence for this clausal analysis comes from the existence of the intermediate form dare-ka-sira 'someone', in which only the negation -nai is deleted, with the verb 'know' left intact (see Hiraiwa \& Nakanishi to appear).

\footnotetext{
${ }^{3}$ For fairness, it should be noted that Takita (2009) argues for the wh-movement analysis based on sluicing with non-finite complements. I will not discuss his argument and its potential problems here, but the evidence from the immobility of certain wh-adjuncts and NCIs indicate that sluicing in Japanese cannot be derived from wh-movement. ${ }^{4}$ I am very grateful to Tommy Tsz-Ming Lee for pointing out this fact to me.

${ }^{5}$ See Hiraiwa \& Nakanishi (2020) for a theory of bare indeterminates.
} 
Given the hypothesis in (23), existential indeterminates are contingent on sluicing. Because sluicing in Japanese has a wh-cleft structure, as we have seen above, it is predicted that existential indeterminates should also be ungrammatical, if their indeterminates cannot be whclefted, either. We have already shown that nandemata and nandatte are indeed disallowed in wh-cleft in (11)-(12). Therefore, it follows that they cannot form existential indeterminates, either, as shown in (22). Thus, a wh-cleft analysis can correctly predict the otherwise unexpected asymmetry between (20)-(21) and (22).

5. Conclusion. In this paper, building on immobile wh-adjuncts and NCIs, I have demonstrated that sluicing in Japanese cannot apply in-situ. Whenever a wh-phrase cannot be focused in wh-cleft, sluicing is ungrammatical. If sluicing applied in-situ, sluicing with such an immobile wh-phrase should be licit. Similarly, NCIs, which cannot be focused in wh-cleft, do not allow sluicing.These facts provide clear evidence against the in-situ deletion analysis as well as the wh-movement analysis of sluicing. Furthermore, whenever a wh-phrase can be focused in wh-cleft, sluicing is grammatical. This supports the wh-cleft analysis of sluicing.

\section{References}

Abe, Jun. 2015. The in-situ approach to sluicing. Amsterdam/Philadelphia: John Benjamins.

Abe, Jun. 2016. Make short answers shorter: Support for the in-situ approach. Syntax 19(3). 223255. https://doi.org/10.1111/synt.12124.

van Craenenbroeck, Jeroen \& Marcel den Dikken. 2006. Ellipsis and EPP repair. Linguistic Inquiry 37(4). 653-664. https://doi.org/10.1162/ling.2006.37.4.653.

den Dikken, Marcel, André Meinunger \& Chris Wilder. 2002. Pseudoclefts and ellipsis. Studia Linguistica 54(1). 41-89. https://doi.org/10.1111/1467-9582.00050.

Fujii, Tomohiro, Kensuke Takita, Barry Chung-Yu Yang \& Wei-Tien Dylan Tsai. 2014. Comparative remarks on wh-adverbials in situ in Japanese and Chinese. In Mamoru Saito (ed.), Japanese syntax in comparative perspective, 181-205. New York, NY: Oxford University Press. https://doi.org/10.1093/acprof:oso/9780199945207.003.0007.

Fukaya, Teruhiko \& Hajime Hoji. 1999. Stripping and sluicing in Japanese and some implications. In Sonya Bird, Andrew Carnie, Jason D. Haugen \& Peter Norquest (eds.), The proceedings of WCCFL 18, 145-158. Somerville, MA: Cascadilla Press.

Fukui, Naoki. 1998. LF extraction of naze: Some theoretical implications. Natural Language \& Linguistic Theory 6(4). 503-526. https://doi.org/10.1007/BF00134490.

Haspelmath, Martin. 1997. Indefinite pronouns. Oxford: Oxford University Press.

Hiraiwa, Ken. 2015. The QP syntax: Noun class, case, and augment. In Thuy Bui \& Deniz O” zidiz (eds.), Proceedings of NELS 45, 1-11. Amherst, MA: GLSA.

Hiraiwa, Ken. 2017. Labeling roots: Indeterminates and particles. In Andrew Lamont \& Katerina Tetzloff (eds.), Proceedings of NELS 47 (Volume 2), 79-88. Amherst, MA: GLSA.

Hiraiwa, Ken. 2020. The origin and architecture of existential quantifiers in Okinawan. Proceedings of the Linguistic Society of America 5(1). 384-389. https://doi.org/10.3765/plsa.v5i1.4705.

Hiraiwa, Ken \& Shinichiro Ishihara. 2012. Syntactic metamorphosis: Clefts, sluicing, and in-situ 
focus in Japanese. Syntax 15(2). 142-180. https://doi.org/10.1111/j.1467-9612.2011.00164.x. Hiraiwa, Ken \& Kimiko Nakanishi. 2020. Bare indeterminates in unconditionals. Proceedings of the Linguistic Society of America 5(1). 395-409. https://doi.org/10.3765/plsa.v5i1.4706.

Hiraiwa, Ken \& Kimiko Nakanishi. To appear. Free choice and existential indeterminates in Japanese as hidden clauses. The proceedings of WAFL 15. Cambridge, MA: MITWPL.

Inoue, Kazuko. 1976. Henkeibunpoo to nihongo (Transformational grammar and Japanese). Tokyo: Taishukan.

Kimura, Hiroko. 2010. A wh-in-situ strategy for sluicing. English Linguistics 27. 43-59. https://doi.org/10.9793/elsj.27.143.

Kimura, Hiroko \& Hiroki Narita. 2021. Compound wh-questions and fragment answers in Japanese: Implications for the nature of ellipsis. Linguistic Inquiry 52(1). 195-209. https://doi.org/10.1162/ling a 00362 .

Kizu, Mika. 2005. Cleft constructions in Japanese syntax. New York: Palgrave Macmillan.

Ko, Heejeong. 2005. Syntax of Wh-in-situ: Merge into [Spec, CP] in the overt syntax. Natural Language \& Linguistic Theory 23. 867-916. https://doi.org/10.1007/s11049-004-5923-3.

Kuroda, S.-Y. 1965. Generative grammatical studies in the Japanese language. Cambridge, MA: MIT dissertation.

Kuwabara, Kazuki. 1997. On the properties of truncated clauses in Japanese. In Researching and verifying an advanced theory of human language: Explanation of the human faculty for constructing and computing sentences on the basis of lexical conceptual features, 61-83. Chiba: Kanda University of International Studies.

Merchant, Jason \& Andrew Simpson (eds.). 2012. Sluicing: Cross-linguistic perspectives. New York, NY: Oxford University Press.

Nishiyama, Kunio, John Whitman \& Eun-Young Yi. 1996. Syntactic movement of overt Whphrases in Japanese and Korean. In Japanese/Korean linguistics 5, 337-351. Stanford, CA: CSLI.

Ross, John Robert. 1969. Guess who? In Robert I. Binnick, Alice Davison, Georgia M. Green \& James L. Morgan (eds.), The proceedings of CLS 5, 252-286. Chicago: Chicago Linguistic Society.

Saito, Mamoru. 2004. Ellipsis and pronominal reference in Japanese clefts. Nanzan Linguistics 1. 21-50.

Sato, Yosuke. 2016. An in-situ syntax of sluicing in Indonesian. In Hiroki Nomoto, Takuya Miyauchi \& Asako Shiohara (eds.), The proceedings of AFLA 23, 243-257. Canberra: The Australian National University.

Shimoyama, Junko. 2008. Indeterminate pronouns. In Shigeru Miyagawa \& Mamoru Saito (eds.), The Oxford handbook of Japanese linguistics, 372-393. New York, NY: Oxford University Press. https://doi.org/10.1093/oxfordhb/9780195307344.013.0014.

Takahashi, Daiko. 1994. Sluicing in Japanese. Journal of East Asian Linguistics 3(3). 265-300. https://doi.org/10.1007/BF01733066.

Takita, Kensuke. 2009. 'Genuine' sluicing in Japanese. Proceedings of the Chicago Linguistic Society (CLS) 45(1). 577-593.

Tanaka, Hidekazu. 1997. Invisible movement in sika-nai and the linear crossing constraint. Journal of East Asian Linguistics 6. 143-188. https://doi.org/10.1023/A:1008202213790.

Watanabe, Akira. 2004. The genesis of negative concord: Syntax and morphology of negative doubling. Linguistic Inquiry 35(4). 559-612. https://doi.org/10.1162/0024389042350497. 